\title{
Feijão-vagem semeado sobre cobertura viva perene de gramínea e leguminosa e em solo mobilizado, com adubação orgânica
}

\author{
Nelson Geraldo de Oliveira ${ }^{(1)}$, Helvécio De-Polli(1), Dejair Lopes de Almeida ${ }^{(1)}$ e José Guilherme Marinho Guerra(1)
}

Embrapa Agrobiologia, BR 465, Km 07, CEP 23890-000 Seropédica, RJ. E-mail: ngoufrrj@yahoo.com.br, depolli@cnpab.embrapa.br, dejair@cnpab.embrapa.br, gmguerra@cnpab.embrapa.br

\begin{abstract}
Resumo - O objetivo deste trabalho foi avaliar o desempenho agronômico do feijão-vagem, cv. Alessa, cultivado sobre cobertura viva perene de grama-batatais (Paspalum notatum Flüggé) e de amendoim forrageiro (Arachis pintoi Krapov \& Gregory), e em solo convencionalmente preparado, como controle. Diferentes doses de cama de aviário (0, 7, 14 e $28 \mathrm{t} \mathrm{ha}^{-1}$ ) foram fornecidas, parceladamente, em um Planossolo, em Seropédica, RJ, de agosto a outubro de 2002. O delineamento adotado foi o de blocos ao acaso, dispostos em parcelas subdivididas, com quatro repetições, utilizando-se modelo quadrático para análise dos resultados. A produtividade de vagens foi semelhante nos três sistemas de cultivo sem efeito competitivo das espécies de cobertura viva, sobre as quais foi realizada a semeadura direta da cultura, com enxada. A produtividade máxima estimada pelo modelo de regressão foi 20,3 t ha ${ }^{-1}$ de vagens. Esse valor foi obtido com a dose de 26 t ha $^{-1}$ de cama de aviário, aplicada de forma parcelada. A semeadura direta de feijão-vagem sobre cobertura viva perene de grama-batatais e de amendoim forrageiro é viável, com resultados preliminares positivos.
\end{abstract}

Termos para indexação: Phaseolus vulgaris, Paspalum notatum, Arachis pintoi, cultivo orgânico, adubação orgânica.

\section{Snap bean planted on living perennial mulch of grass and legume and in tilled soil with organic amendment}

\begin{abstract}
The objective of this work was to evaluate the agronomic performance of snap bean planted on living perennial mulch of bahia grass (Paspalum notatum Flüggé) and of peanut (Arachis pintoi Krapov \& Gregory) and in a conventional tillage soil as a control. Different parcels and doses of poultry bed manure (0, 7, 14 and $28 \mathrm{t} \mathrm{ha}^{-1}$ ) were used in a Planosol soil from August to October of 2002. The statistical design was a split plot, in completely randomized blocks, with four replications, using a quadratic model to analyze the results. Snap bean yield was similar for the tillage system treatments without competition effect from the living mulch, in which direct seeding of the main crop was performed with a hoe. The greatest snap bean yield estimated by regression model was $20.3 \mathrm{t} \mathrm{ha}^{-1}$, corresponding to the dose of $26 \mathrm{t} \mathrm{ha}^{-1}$ of manure applied in parcels. The direct seeding of snap bean on living perennial mulch of bahia grass and perennial peanut is agronomicaly viable, with positive preliminary results on snap bean yield.
\end{abstract}

Index terms: Phaseolus vulgaris, Paspalum notatum, Arachis pintoi, organic crop, organic fertilization.

\section{Introdução}

Solos agrícolas das regiões tropicais e subtropicais, expostos a condições climáticas intensas, necessitam de proteção contínua. A movimentação do solo e sua exposição direta à ação do clima provocam a erosão, com perda de nutrientes e redução dos teores de matéria orgânica, o que leva à degradação do solo e redução na produtividade agrícola (Calegari et al., 1993).

O desenvolvimento de alternativas de manejo e proteção do solo é objeto de variadas linhas de pesquisa, além disso também são estudadas práticas com as quais seja possível promover a sustentabilidade dos sistemas produtivos (De-Polli et al., 1996)

A cobertura viva perene minimiza o impacto prejudicial causado pelos efeitos adversos do clima nos sistemas de produção. As coberturas vivas perenes, além de potencial para contribuição na melhoria das características físicas, químicas e biológicas do solo, também atuam positivamente no controle natural da vegetação espontânea, na mobilização e reciclagem de nutrientes e no favorecimento da atividade biológica do solo (Barradas et al., 2001; Duda et al., 2003; Castro et al., 2004; Faria et al., 2004). Esses benefíci- 
os contribuem para maior estabilidade do sistema produtivo e diminuição dos custos de produção. Outras vantagens da utilização de cobertura viva sobre o solo, destacadas por De-Polli et al. (1996), são a redução das perdas de água por evaporação, o auxílio no controle da erosão e a formação de ambiente favorável aos organismos do solo.

Quantidades adequadas de material orgânico podem ser acrescentadas ao solo com a grama-batatais, principalmente suas raízes e rizomas (Espindola et al., 1997). Além disso, em decorrência de associações com bactérias diazotróficas, Azotobacter paspali, é possível o enriquecimento do solo com $\mathrm{N}$ derivado da fixação biológica (De-Polli et al., 1977; Giller \& Wilson, 1991).

O uso de leguminosas como adubo verde traz grande benefício ao solo pelo aumento do $\mathrm{N}$ disponível no sistema, por meio da fixação biológica do $\mathrm{N}$ atmosférico (FBN) (Freire, 1992). Sob condições favoráveis, em algumas leguminosas, os índices da FBN são superiores a $90 \%$ do $\mathrm{N}$ total da planta (Oliveira et al., 1996), com disponibilizacão posterior desse $\mathrm{N}$ para a cultura a elas consorciadas. Dessa forma, o processo de fixação biológica pode substituir o uso de adubos minerais no fornecimento de $\mathrm{N}$ para várias culturas (Smyth et al., 1991).

Em condições de campo, Perin (2001) obteve, ao utilizar o amendoim forrageiro (Arachis pintoi Krapov \& Gregory), produção de matéria seca equivalente a $20 \mathrm{t} \mathrm{ha}^{-1}$, no período de 24 meses desde a semeadura. Por meio desses dados, o autor calculou uma adição de cerca de $270 \mathrm{~kg} \mathrm{ha}^{-1}$ de $\mathrm{N}$ ao sistema; essa quantidade foi disponibilizada continuamente no processo de mineralização. Porém, a identificação e a adequação de leguminosas herbáceas perenes, para a utilização como cobertura viva do solo, é ainda um desafio. O sucesso dessa prática depende, entre outros fatores, de conhecimentos sobre o comportamento, adaptação e exigência de cada espécie no manejo adotado.

Na semeadura direta sobre cobertura viva perene e sistema de manejo orgânico, não é permitido o uso de herbicida. Esse sistema está de acordo com o Centro de Cooperação Internacional Agronômica para o Desenvolvimento (2002), adequando-se às normas de certificação da agricultura orgânica. A cultura do feijão-vagem de porte determinado do tipo I é uma opção de diversificação para a atividade hortícola em regiões do Brasil, e se constitui numa cultura de manejo simplificado, quando comparada ao feijão-vagem de porte indeterminado do tipo IV (Lopes et al., 2004) .
O objetivo deste trabalho foi avaliar os rendimentos do feijão-vagem (Phaseolus vulgaris L.), semeado diretamente sobre cobertura viva perene de gramabatatais e de amendoim forrageiro, e em solo com preparo convencional, com adição de doses de adubo orgânico em cobertura, visando a definição de um eficiente sistema de produção.

\section{Material e Métodos}

O trabalho foi realizado no Sistema Integrado de Produção Agroecológica (SIPA - Fazendinha Agroecológica Km 47), unidade de pesquisa em produção orgânica, em Seropédica, RJ. A Fazendinha Agroecológica Km 47 situa-se a 2246'S e $43^{\circ} 41^{\prime} \mathrm{O}$, a $33 \mathrm{~m}$ de altitude (Almeida et al., 1999). As temperaturas da região são amenas no inverno, que é seco e elevadas no verão, com taxa de precipitação pluvial média anual em torno de 1.200 mm (Golfari \& Moosmayer, 1980).

O trabalho foi desenvolvido de agosto a outubro de 2002, tendo sido implantado em um Planossolo Háplico distrófico (Embrapa, 1999), cujos resultados da análise química foram: $\mathrm{pH}$ em água, 5,5; $\mathrm{Al}^{3+}, 0,0 \mathrm{cmol}_{\mathrm{c}} \mathrm{dm}^{-3}$; $\mathrm{Ca}^{2+}, 1,4 \mathrm{cmol}_{\mathrm{C}} \mathrm{dm}^{-3} ; \mathrm{Mg}^{2+}, 0,9 \mathrm{cmol}_{\mathrm{C}} \mathrm{dm}^{-3} ; \mathrm{K}^{+}$, $26 \mathrm{mg} \mathrm{dm}^{-3} ; \mathrm{P}, 13 \mathrm{mg} \mathrm{dm}^{-3}$; C, 5,7 $\mathrm{g} \mathrm{kg}^{-1}$; N, 0,76 g kg-1.

O delineamento experimental adotado foi o de blocos ao acaso, em esquema de parcelas subdivididas, com quatro repetições. Em parcelas com área de $32 \mathrm{~m}^{2}$, com dimensões de $8 \times 4 \mathrm{~m}$, foram avaliados três sistemas de cultivo, constituídos por semeadura direta sobre cobertura viva perene de grama-batatais (Paspalum notatum Flüggé) e de amendoim forrageiro (Arachis pintoi Krapov \& Gregory), e por semeadura, em solo preparado com enxada rotativa, como controle. Nas subparcelas, com área de $8 \mathrm{~m}^{2}$, avaliaram-se doses de $0,7,14$ e 28 t ha ${ }^{-1}$ de cama de aviário, aplicadas em cobertura e parceladamente, em quatro aplicações, aos 15, 22, 30 e 37 dias depois da semeadura.

Espécies para cobertura viva foram instaladas na área, sem qualquer tipo de adubação, em janeiro de 2002, por meio de mudas de grama-batatais e sementes de amendoim forrageiro, cv. Amarillo, respectivamente nas densidades de $0,1 \times 0,1 \mathrm{~m}$ entre covas e 12 sementes por metro linear, em sulcos com espaços de $0,5 \mathrm{~m}$. O manejo da fitomassa foi efetuado com auxílio de roçadora costal, à altura média de $5 \mathrm{~cm}$, um dia antes da semeadura da cultura principal.

Essa cultura foi de feijão-vagem (Phaseolus vulgaris), cv. Alessa, semeada em 28 de agosto de 2002, 
em sulcos abertos, com auxílio de enxada, e espaços de em $0,5 \mathrm{~m}$, na densidade de dez sementes por metro linear, em área adubada com $10 \mathrm{tha}^{-1}$ de esterco bovino, contendo $17 \mathrm{~g} \mathrm{~kg}^{-1}$ de $\mathrm{N}$ total e $42,3 \%$ de umidade, aplicadas na semeadura.

As sementes foram submetidas à inoculação de estirpes de rizóbio selecionadas para a cultura, imediatamente antes da semeadura. A adubação de cobertura foi feita na linha de semeadura, aos 15, 22, 30 e 37 dias depois da semeadura, com cama de aviário com a composição: 16,3\% de umidade, $\mathrm{pH}$ em água,

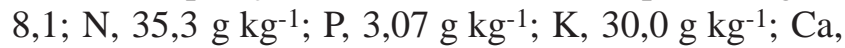
48,3 $\mathrm{g} \mathrm{kg}^{-1}$; Mg, 5,5 $\mathrm{g} \mathrm{kg}^{-1}$; C, $474 \mathrm{~g} \mathrm{~kg}^{-1}$.

Nas subparcelas referentes ao solo mobilizado, foram realizadas duas capinas na cultura do feijão-vagem, aos 15 e 30 dias depois da semeadura. Nas subparcelas instaladas diretamente sobre as coberturas vivas perenes as capinas foram dispensadas.

Na área experimental, foi utilizada irrigação localizada, do tipo microaspersão, sendo aplicada uma lâmina de irrigação de $6 \mathrm{~mm}$ por dia. Os parâmetros avaliados na cultura do feijão-vagem foram os teores de N (Alves et al., 1994), P, K, Ca e Mg (Bataglia et al., 1983), nos tecidos da folha índice e da vagem verde, segundo Trani \& Raij (1996), além da produtividade de vagens verdes e sua matéria seca.

As vagens verdes do feijão foram colhidas numa única vez, aos 55 dias após a semeadura, em 24 de outubro de 2002. Avaliou-se a produtividade de matéria seca a partir de amostras de aproximadamente $300 \mathrm{~g}$ de vagens verdes, posteriormente secadas em estufa a $65^{\circ} \mathrm{C}$ até peso constante.

Os dados obtidos foram submetidos à análise de variância, aplicando-se o teste $\mathrm{F}$, comparação de médias pelo teste de Scott-Knott a 5\% de probabilidade, e análise de regressão por meio do SISVAR (Ferreira, 2000).

\section{Resultados e Discussão}

Não houve diferença significativa quanto aos teores de N, P, K e Mg no tecido da folha índice de feijãovagem, na comparação entre os três diferentes sistemas de cultivo avaliados (Tabela 1). Em doses crescentes de cama de aviário aplicadas em cobertura, observou-se efeitos significativos quanto aos teores totais de $\mathrm{N}, \mathrm{P}, \mathrm{K}(\mathrm{p}<0,01)$ e os de Mg ( $<<0,05)$ (Figura 1$)$.

Os teores de N, P, K e Mg, na folha índice, variaram, respectivamente, de 31,2 a 42,2 $\mathrm{g} \mathrm{kg}^{-1}, 2,9$ a $4,8 \mathrm{~g} \mathrm{~kg}^{-1}$, 13,8 a 22,2 $\mathrm{g} \mathrm{kg}^{-1}, 4,4$ a 5,6 $\mathrm{g} \mathrm{kg}^{-1}$. Trani \& Raij (1996) indicam, como faixas de teores adequados, 40 a $60 \mathrm{~g} \mathrm{~kg}^{-1}$ de N; 3 a 7 g kg$^{-1}$ de P; 25 a 40 g kg$^{-1}$ de Ke 3 a 8 g kg$^{-1}$ de Mg. Constatou-se que os teores de $\mathrm{N}$ e $\mathrm{K}$ dos dados obtidos são inferiores aos valores citados por Trani \& Raij (1996), porém, não observou-se redução na produtividade. Os teores de $\mathrm{P}$ e $\mathrm{Mg}$ foram equivalentes aos teores citados.

Houve efeito significativo $(\mathrm{p}<0,01)$ quanto ao teor de Ca na folha índice de feijão-vagem em relação ao sistema de cultivo (Tabela 1), constatando-se no preparo convencional, aumento de 32,3\% na concentração desse nutriente, comparado às médias obtidas no sistema de cultivo direto sobre cobertura viva perene. Porém, este incremento de Ca na folha índice não ocasionou aumento correspondente na produtividade (Tabela 2), nem efeito significativo $(\mathrm{p}<0,05)$ quanto ao $\mathrm{Ca}$, em relação às doses crescente de cama de aviário aplicada em cobertura (Figura 1).

Os teores de Ca na matéria seca do tecido foliar foram variáveis entre 17,5 e 27,8 $\mathrm{g} \mathrm{kg}^{-1}$, sendo considerados adequados, conforme a faixa de 15 a $30 \mathrm{~g} \mathrm{~kg}^{-1}$, indicada por Trani \& Raij (1996).

Na comparação de diferentes sistemas de cultivo, não se constatou diferença significativa $(p<0,05)$ quanto aos teores de $\mathrm{P}, \mathrm{K}$, Ca e Mg no tecido da vagem verde (Tabela 3). Em relação às doses crescentes de cama

Tabela 1. Teores médios de nitrogênio, fósforo, potássio, cálcio e magnésio no tecido foliar de feijão-vagem, cv. Alessa, semeado diretamente sobre cobertura viva perene da gramínea grama-batatais (Paspalum notatum) e da leguminosa amendoim forrageiro (Arachis pintoi) e em solo com preparo convencional com adubação orgânica de cobertura(1).

\begin{tabular}{|c|c|c|c|c|c|}
\hline Tratamento & $\mathrm{N}$ & $\mathrm{P}$ & $\mathrm{K}$ & $\mathrm{Ca}$ & $\mathrm{Mg}$ \\
\hline & ---------. & --------- & $-\mathrm{g} \mathrm{kg}^{-1}$ & - ------ & - \\
\hline Grama batatais & $35,48 \mathrm{~A}$ & $3,91 \mathrm{~A}$ & $18,95 \mathrm{~A}$ & $20,52 \mathrm{~B}$ & $5,05 \mathrm{~A}$ \\
\hline Amendoim forrageiro & $36,16 \mathrm{~A}$ & $4,25 \mathrm{~A}$ & $18,24 \mathrm{~A}$ & $20,68 \mathrm{~B}$ & $4,96 \mathrm{~A}$ \\
\hline Preparo convencional & $36,01 \mathrm{~A}$ & $3,85 \mathrm{~A}$ & $19,65 \mathrm{~A}$ & $27,26 \mathrm{~A}$ & $5,05 \mathrm{~A}$ \\
\hline CV $(\%)$ & 10,1 & 9,6 & 14,6 & 15,4 & 10,1 \\
\hline
\end{tabular}

(1)Médias seguidas por letras distintas nas colunas são diferentes entre si pelo teste de Scott-Knott a 5\% de probabilidade; valores médios de quatro doses de cama de aviário (0, 7, 14 e 28 t ha-1), aplicadas em cobertura. 
de aviário aplicadas em cobertura, não houve efeitos significativos para $\mathrm{N}, \mathrm{K}$, Ca e Mg.

Nos diferentes sistema de cultivo, os efeitos foram significativos $(\mathrm{p}<0,05)$ apenas para o teor total de $\mathrm{N}$ no tecido da vagem verde (Tabela 3 ), sobretudo naquele
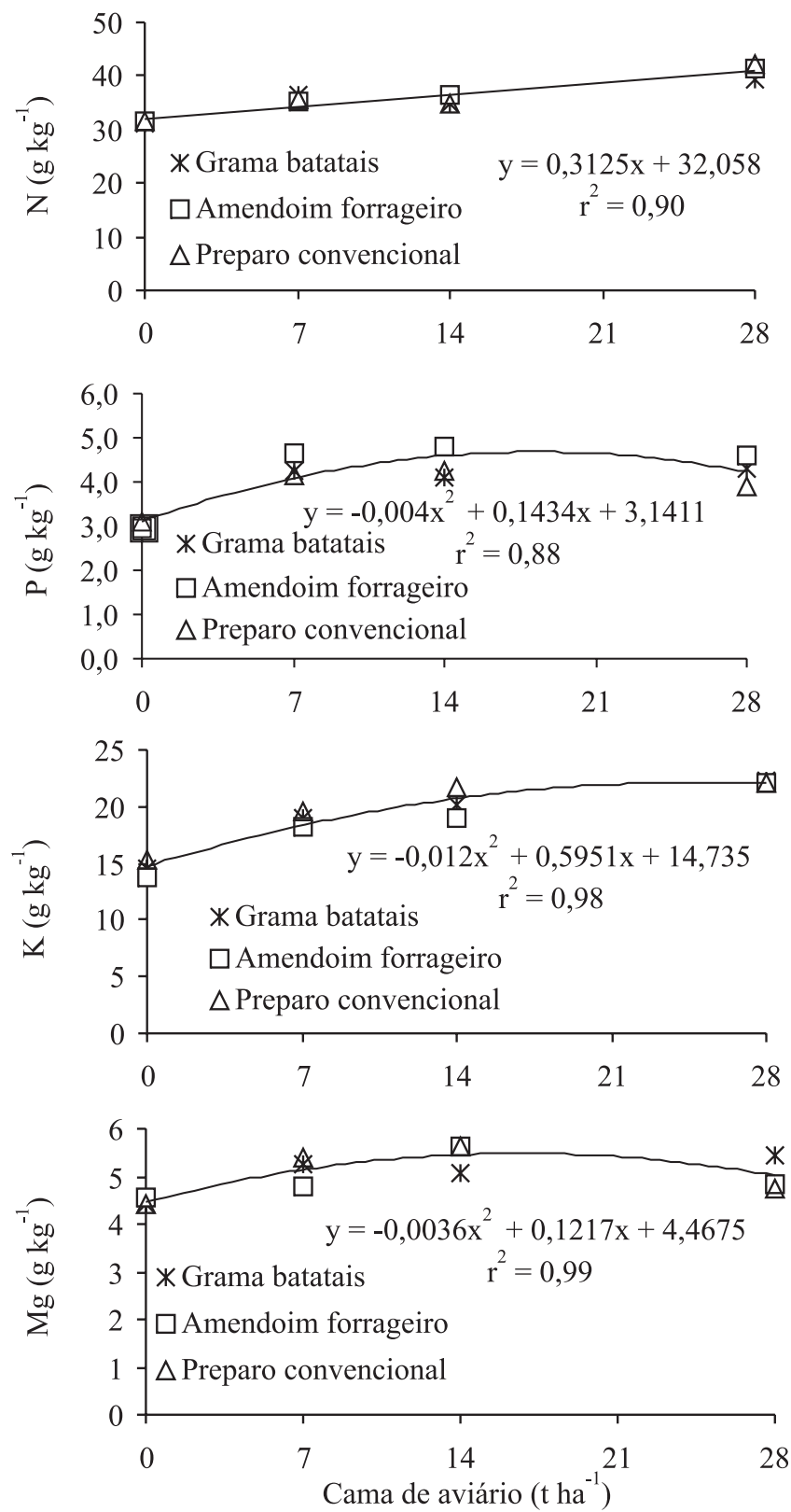

Figura 1. Teores de nitrogênio, fósforo, potássio e magnésio no tecido foliar de feijão-vagem, cv. Alessa, semeado diretamente sobre cobertura viva perene da gramínea grama-batatais (Paspalum notatum) e da leguminosa amendoim forrageiro (Arachis pintoi) e em solo com preparo convencional, em função de doses crescentes de adubo orgânico aplicadas em cobertura. com cobertura viva de amendoim forrageiro. Doses crescentes de cama de aviário aplicadas em cobertura produziram efeitos significativos ( $<<0,01$ ) para $\mathrm{P}$ (Figura 2). $\mathrm{O}$ aumento do teor de $\mathrm{P}$ no tecido de vagem foi coerente com o incremento desse nutriente por meio da adubação orgânica, o que implica maior disponibilidade de $\mathrm{P}$ no solo. Ao contrário dos demais nutrientes, a translocação de $P$ para vagens foi influenciada positivamente pelo aumento da dose de cama de aviário, associada com a lâmina de água de $6 \mathrm{~mm}$ por dia de irrigação, corroborando os dados de Silveira \& Moreira (1990), que concluíram que o conteúdo de $\mathrm{P}$ na planta elevouse com o aumento da dose de P e da lâmina de água.

A diferença significativa de concentração de Ca no tecido das folhas índice, decorrente de diferentes sistemas de cultivo, não foi equivalente no tecido de vagem (Tabela 3), com variação de 5,39 a 7,09 g kg-1, corroborando com os teores de 4,46 a $6,07 \mathrm{~g} \mathrm{~kg}^{-1}$, constatados por Miglioranza et al. (1997), e os de 3,82 a $6,80 \mathrm{~g} \mathrm{~kg}^{-1}$, em 64 genótipos de feijão-vagem, por Quintana et al. (1999).

Segundo Miglioranza et al. (1997) e Quintana et al. (1999), o acúmulo de Ca em tecido de vagem verde pode ser semelhante, desde que no solo haja suficiente quantidade do nutriente, ou seja, um teor médio de $\mathrm{Ca}^{2+}$ igual a $4,00 \mathrm{cmol}_{\mathrm{C}} \mathrm{dm}^{-3}$.

Em todos os sistemas de cultivo foram detectados aumentos significativos $(\mathrm{p}<0,05)$ de produtividade de vagens verdes com o aumento das doses do adubo orgânico aplicado em cobertura (Figura 3), mas não na produção de matéria seca das vagens (Tabela 3). A produtividade máxima estimada pelo modelo de regressão foi 2,15 t ha-1 de matéria seca de vagem, com a dose de 25,13 tha-1 de cama de aviário (Figura 3).

Tabela 2. Produtividade média de massa fresca e seca de frutos de feijão-vagem, cv. Alessa, semeado diretamente sobre cobertura viva perene da gramínea grama-batatais (Paspalum notatum) e da leguminosa amendoim forrageiro (Arachis pintoi) e em solo com preparo convencional com adubação orgânica de cobertura(1).

\begin{tabular}{|c|c|c|}
\hline Tratamento & Matéria fresca & Matéria seca \\
\hline & \multicolumn{2}{|c|}{ - } \\
\hline Grama batatais & $15,85 \mathrm{~A}$ & $1,75 \mathrm{~A}$ \\
\hline Amendoim forrageiro & $13,49 \mathrm{~A}$ & $1,29 \mathrm{~A}$ \\
\hline Preparo convencional & $15,73 \mathrm{~A}$ & $1,93 \mathrm{~A}$ \\
\hline $\mathrm{CV}(\%)$ & 38,6 & 38,9 \\
\hline
\end{tabular}

(1)Médias seguidas por letras distintas nas colunas são diferentes entre si pelo teste de Scott-Knott a 5\% de probabilidade; valores médios de quatro doses de cama de aviário (0, 7, 14 e 28 t ha-1), aplicadas em cobertura. 
Tabela 3. Teores médios de nitrogênio, fósforo, potássio, cálcio e magnésio no tecido de vagem verde de feijão-vagem, cv. Alessa, semeado diretamente sobre cobertura viva perene da gramínea grama-batatais (Paspalum notatum) e da leguminosa amendoim forrageiro (Arachis pintoi) e em solo com preparo convencional com adubação orgânica de cobertura ${ }^{(1)}$.

\begin{tabular}{lcccc}
\hline Tratamento & $\mathrm{N}$ & $\mathrm{P}$ & $\mathrm{K}$ & $\mathrm{Ca}$ \\
\hline & - & $\mathrm{Mg}$ & \\
Grama batatais & $29,56 \mathrm{~B}$ & $5,22 \mathrm{~A}$ & $26,09 \mathrm{~A}$ & $6,17 \mathrm{~A}$ \\
Amendoim forrageiro & $32,77 \mathrm{~A}$ & $5,06 \mathrm{~A}$ & $24,88 \mathrm{~A}$ & $6,32 \mathrm{~A}$ \\
Preparo convencional & $29,52 \mathrm{~B}$ & $4,65 \mathrm{~A}$ & $25,72 \mathrm{~A}$ & $6,13 \mathrm{~A}$ \\
\hline CV $(\%)$ & 9,3 & 13,8 & 18,9 & 27,6 \\
\hline
\end{tabular}

(1)Médias seguidas por letras distintas nas colunas são diferentes entre si pelo teste de Scott-Knott a 5\% de probabilidade; valores médios de quatro doses de cama de aviário (0, 7, 14 e $\left.25 \mathrm{t} \mathrm{ha}^{-1}\right)$, aplicadas em cobertura.

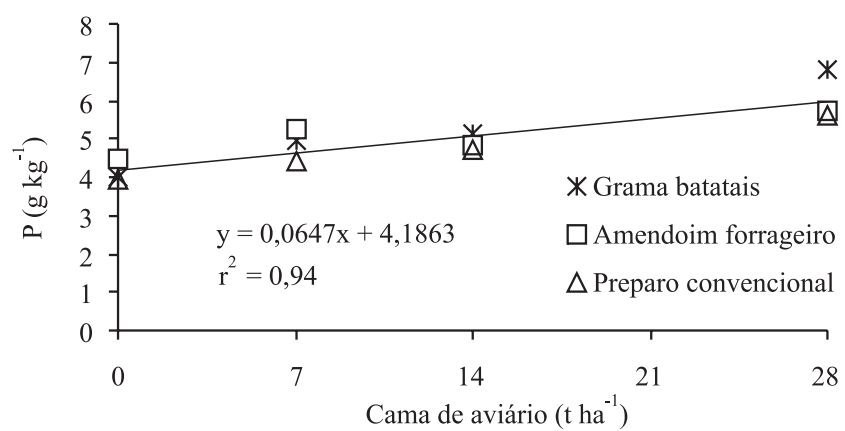

Figura 2. Teores de fósforo no fruto de feijão-vagem, cv. Alessa, semeado diretamente sobre cobertura viva perene da gramínea grama-batatais (Paspalum notatum) e da leguminosa amendoim forrageiro (Arachis pintoi) e em solo com preparo convencional, em função de doses crescentes de adubo orgânico aplicadas em cobertura.
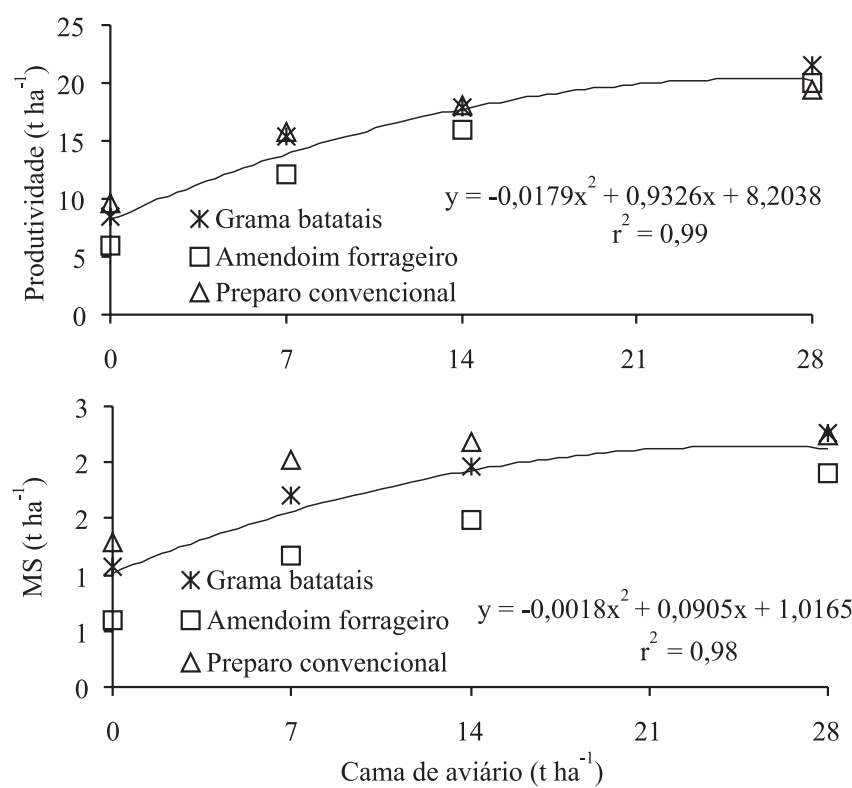

Figura 3. Produtividade e matéria seca de frutos de feijão-vagem, cv. Alessa, semeado diretamente sobre coberturas vivas perenes da gramínea grama-batatais (Paspalumnotatum) e da leguminosa amendoim forrageiro (Arachis pintoi) e em solo com preparo convencional, em função de doses crescentes de adubo orgânico aplicadas em cobertura.
Quanto à produtividade de vagens verdes, o valor máximo estimado pelo modelo de regressão foi 20,3 $\mathrm{t} \mathrm{ha}^{-1}$, na dose de 26 t ha $^{-1}$ (Figura 3). Existe potencial de produção, no sistema de cultivo orgânico adotado, com cultivar de porte determinado do tipo 1 , cuja produtividade foi equivalente à de cultivar de feijão-vagem de porte indeterminado, do tipo 4 que, segundo Trani \& Raij (1996), é de 20 a $25 \mathrm{t} \mathrm{ha}^{-1}$.

Verifica-se a possibilidade da produção de feijão-vagem, em semeadura direta sobre cobertura viva perene de grama-batatais e de amendoim forrageiro, particularmente quando são adicionadas doses elevadas, superiores a $20 \mathrm{t} \mathrm{ha}^{-1}$ de adubo orgânico, especificamente do tipo cama de aviário.

Pesquisas demonstram a possibilidade de resolver problemas ambientais associados à prática da agricultura convencional, com a semeadura de culturas sobre cobertura viva (Texto..., 2005). No entanto, o crescimento da planta e a produtividade podem ser reduzidos neste sistema, provavelmente em virtude da competição por água e nutrientes no sistema radicular da planta associada, conforme constatado na cultura do milho por Liedgens et al. (2004a, 2004b). Neste trabalho, isto não foi evidenciado, pois as produtividades obtidas com o feijão-vagem cultivado sobre as duas espécies de cobertura viva foram estatisticamente comparáveis às da verificada no sistema controle, em solo mobilizado sem cobertura viva. $\mathrm{O}$ uso adequado da irrigação, bem como o de doses adequadas de adubos orgânicos, podem ser parte da explicação, além de eventual adequação dos sistemas radiculares das plantas envolvidas.

\section{Conclusão}

O cultivo do feijão-vagem, cv. Alessa, diretamente sobre cobertura viva perene de grama-batatais e amendoim-forrageiro apresenta viabilidade comparável ao cultivo em solo mobilizado, com adubação orgânica em todas as situações. 


\section{Agradecimentos}

À Capes e à Faperj, pelo apoio financeiro.

\section{Referências}

ALMEIDA, D.L. de; RIBEIRO, R. de L.D.; GUERRA, J.G.M. Sistema integrado de produção agroecológica: "Fazendinha Agroecológica km 47”. In: SIMPÓSIO DE AGRICULTURA ECOLÓGICA， 2.; ENCONTRO DE AGRICULTURA ORGÂNICA, 1., 1999, São Paulo. Anais. Guaíba: Agropecuária, 1999. p.153-159.

ALVES, B.J.R.; SANTOS, J.C.F.; URQUIAGA, S.; BODDEY, R.M. Método de determinação do nitrogênio em solo e planta. In: HUNGRIA, M.; ARAÚJO, R.S. (Ed.). Manual de métodos empregados em estudos de microbiologia agrícola. Brasília: Embrapa-SPI; Goiânia: Embrapa-CNPAF; Londrina: EmbrapaCNPSo, 1994. p.449-469. (Embrapa-CNPAF. Documentos, 46).

BARRADAS, C.A.A.; FREIRE, L.R.; ALMEIDA, D.L. de; DE-POLLI, H. Comportamento de alguns adubos verdes de inverno na Região Serrana Fluminense. Pesquisa Agropecuária Brasileira, v.36, p.1461-1468, 2001.

BATAGLIA, O.C.; FURLANI, A.M.C.; TEIXEIRA, J.P.F.; FURLANI, P.R.; GALLO, J.R. Métodos de análises químicas de plantas. Campinas: Instituto Agronômico, 1983. 48p. (Instituto Agronômico. Boletim técnico, 78).

CALEGARI, A.; MONDARDO, A.; BULISANI, E.A.; WILDNER, L.P.; COSTA, M.B.B.; ALCÂNTARA, P.B.; MIYASAKA, S.; AMADO, T.J.C. Adubação verde no Sul do Brasil. 2.ed. Rio de Janeiro: AS-PTA, 1993. 346p.

CASTRO, C.M. de; ALVES, B.J.R.; ALMEIDA, D.L. de; RIBEIRO, R. de L.D. Adubação verde como fonte de nitrogênio para a cultura da berinjela em sistema orgânico. Pesquisa Agropecuária Brasileira, v.39, p.779-785, 2004.

CENTRO DE COOPERAÇÃO INTERNACIONAL AGRONÔMICA PARA O DESENVOLVIMENTO. Departamento de Culturas Anuais. Programa Ecossistemas Cultivados. Para uma agricultura sustentável: o plantio direto sob cobertura permanente. Montpellier, 2002. 2p.

DE-POLLI, H.; GUERRA, J.G.M.; ALMEIDA, D.L. de; FRANCO, A.A. Adubação verde: parâmetros para avaliação de sua eficiência. In: CASTRO FILHO, C. de; MUZILLI, O. (Ed.). Manejo integrado de solos em microbacias hidrográficas. Londrina: Iapar/SBCS, 1996. p.225-242.

DE-POLLI, H.; MATSUI, E.; DÖBEREINER, J.; SALATI, E. Confirmation of nitrogen fixation in two tropical grasses by ${ }^{15} \mathrm{~N}_{2}$ incorporation. Soil Biology and Biochemistry, v.9, p.119-123, 1977.

DUDA, G.P.; GUERRA, J.G.M.; MONTEIRO, M.T.; DE-POLLI, H. Perennial herbaceous legumes as live soil mulches and their effects on C, N and P of the microbial biomass. Scientia Agricola, v.60, p.139-147, 2003.
EMBRAPA. Centro Nacional de Pesquisa de Solos (Rio de Janeiro, RJ). Sistema brasileiro de classificação de solos. Brasília: Embrapa-SPI; Rio de Janeiro: Embrapa-CNPS, 1999. 412p.

ESPINDOLA, J.A.A.; GUERRA, J.G.M.; ALMEIDA, D.L. de. Adubação verde: estratégia para uma agricultura sustentável. Seropédica: Embrapa-CNPAB, 1997. 20p. (Embrapa-CNPAB. Documentos, 42).

FARIA, C.M.B.; SOARES, J.M.; LEÃO, P.C.S. Adubação verde com leguminosas em videira no submédio São Francisco. Revista Brasileira de Ciência do Solo, v.28, p.641-648, 2004.

FERREIRA, D.F. Análises estatísticas por meio do Sisvar para Windows versão 4.0. In: REUNIÃO ANUAL DA REGIÃO BRASILEIRA DA SOCIEDADE INTERNACIONAL DE BIOMETRIA, 45., 2000, São Carlos. Anais. São Carlos: UFSCar, 2000. p.255-258.

FREIRE, J.R.J. Fixação do nitrogênio pela simbiose rizóbio/ leguminosas. In: CARDOSO, E.J.B.N.; TSAI, S.M.; NEVES, M.C.P. (Ed.). Microbiologia do solo. Campinas: SBCS, 1992. p.121-140.

GILLER, K.E.; WILSON, K.J. Nitrogen fixation in tropical cropping systems. Wallingford: CAB International, 1991. 313p.

GOLFARI, L.; MOOSMAYER, H. Manual de reflorestamento do Estado do Rio de Janeiro. Rio de Janeiro: Governo do Estado do Rio de Janeiro, 1980. 110p.

ILNICKI, R.D.; ENZCHE, A.J. Subterranean clover living mulch: an alternative method of weed control. Agriculture Ecosystems and Environment, v.40, p.249-264, 1992.

LIEDGENS, M.; FROSSARD, E.; RICHNER, W. Interactions of maize and Italian ryegrass in a living mulch system. 2. Nitrogen and water dynamics. Plant and Soil, v.259, p.243-258, 2004a.

LIEDGENS, M.; SOLDATI, A.; STAMP, P. Interactions of maize and Italian ryegrass in a living mulch system. 1 . Shoot growth and rooting patterns. Plant and Soil, v.262, p.191-203, 2004b.

LOPES, H.F.; FRANCO, A.A.; ASSIS, R.L. de; DE-POLLI, H. Aspectos econômicos da adubação residual do tomateiro na produção de feijão-de-vagem do médio paraíba fluminense. Agromomia, v.38, p.22-26, 2004.

MIGLIORANZA, E.; BARAK, P.; KMIECIK, K.; NIENHUIS, J. Comparison of soil and genotypic effects on calcium concentration of snap bean pods. HortScience, v.32, p.68-70, 1997.

OLIVEIRA, T.S.; COSTA, L.M. da; REGAZZI, A.J.; FIGUEIREDO, M.S. Efeitos de ciclos de umedecimento e secagem sobre a estabilidade de agregados de quatro Latossolos brasileiros. Revista Brasileira de Ciência do Solo, v.20, p.509-515, 1996.

PERIN, A. Desempenho de leguminosas herbáceas perenes com potencial de utilização como cobertura viva e seus efeitos sobre alguns atributos físicos do solo. 2001. 105p. Dissertação (Mestrado) - Universidade Federal Rural do Rio de Janeiro, Seropédica.

QUINTANA, J.M.; HARRISON, H.C.; NIENHUIS, J.; PALTA, J.P.; KMIECIK, K.; MIGLIORANZA, E. Comparison of pod 
calcium concentration between two snap bean populations. Journal of the American Society for Horticultural Science, v.124, p.273276, 1999.

SILVEIRA, P.M. da; MOREIRA, J.A.A. Resposta do feijoeiro a doses de fósforo e lâmina de água de irrigação. Revista Brasileira de Ciência do Solo, v.14, p.63-67, 1990.

SMYTH, T.J.; CRAVO, M.S.; MELGAR, R.J. Nitrogen supplied to corn by legumes in a Central Amazon Oxisol. Tropical Agriculture, v.68, p.366-372, 1991.

TEXTO provisório da IN que aprovará o regulamento sobre a produção animal e vegetal orgânica. Disponível em: <http://
www.portalagricultura.com.br/Paginas/Agricolas/ visDetalhes.aspx?ch_top=21\&ch_agricola=80>. Acesso em: $19 \mathrm{dez}$. 2005.

TRANI, P.E.; RAIJ, B. van. Hortaliças. In: RAIJ, B. van; CANTARELLA, H.; QUAGGIO, J.A.; FURLANI, A.M.C. Recomendações de adubação e calagem para o Estado de São Paulo. 2.ed. Campinas: IAC, 1996. 285p. (IAC. Boletim técnico, 100).

ZEMENCHIK, R.A.; ALBRECHT, K.A.; BOERBOOM, C.M.; LAUER, J.G. Corn production with kura clover as a living mulch. Agronomy Journal, v.92, p.698-705, 2000.

Recebido em 19 de janeiro de 2006 e aprovado em 30 de maio de 2006 